ropsycological outcome. Ann Thorac Surg 1999; 68: 2202-8.

2 Georgiadis D, Berger A, Kowatschev E, et al. Predictive value of S-100ß and neuron-specific enolase serum levels for adverse neurologic outcome after cardiac surgery. J Thorac Cardiovasc Surg 2000; 119: 138-47.

3 Shaaban Ali M, Harmer M, Vaughan RS. Serum S100 protein as a marker of cerebral damage during cardiac surgery (Letter, reply). Br J Anaesth 2001; 86: 289-90.

4 Fazio V, Bhudia SK, Marchi N, Aumayr B, Janigro D. Peripheral detection of $S 100 \mathrm{~b}$ during cardiothoracic surgery: what are we really measuring? Ann Thorac Surg 2004; 78: 46-53.

\section{Intrathoracic positioning of a thoracic epidural catheter inserted via the median approach}

To the Editor:

Thoracic epidural catheterization for perioperative anesthesia is well-established and used frequently in combination with general anesthesia for abdominal and thoracoabdominal surgery. ${ }^{1}$ A possible complication related to technique, the accidental puncture of the pleural cavity or intrathoracic migration of the catheter has been reported rarely, albeit by the paramedian approach. ${ }^{2}$ We report a case of intrathoracic placement of a thoracic epidural catheter inserted via the median approach.

A thoracic epidural catheter was inserted and advanced $6.5 \mathrm{~cm}$ into the epidural space using a midline approach at the T8-9 level in a 71-yr-old woman undergoing elective esophagectomy and high thoracic esophagogastrostomy. The epidural space was identified easily on the first attempt at $7 \mathrm{~cm}$ by the loss-ofresistance technique. No pain, shortness of breath, cough or shoulder pain and no neurological signs were observed during puncture. During surgery, the catheter was seen to lie in the right pleural cavity. The position of the catheter was documented by a photograph and the catheter was withdrawn immediately. As the photograph demonstrates, the catheter penetrated the parietal pleura close to the spine. The $5.5-\mathrm{cm}$ mark on the catheter cannot be seen in the pleural cavity, which suggests that the point of loss-of-resistance (and therefore the tip of the Tuohy needle) was at least $1 \mathrm{~cm}$ from the parietal pleura. This indicates that the pleural penetration was likely made by the catheter and not by the Tuohy needle.

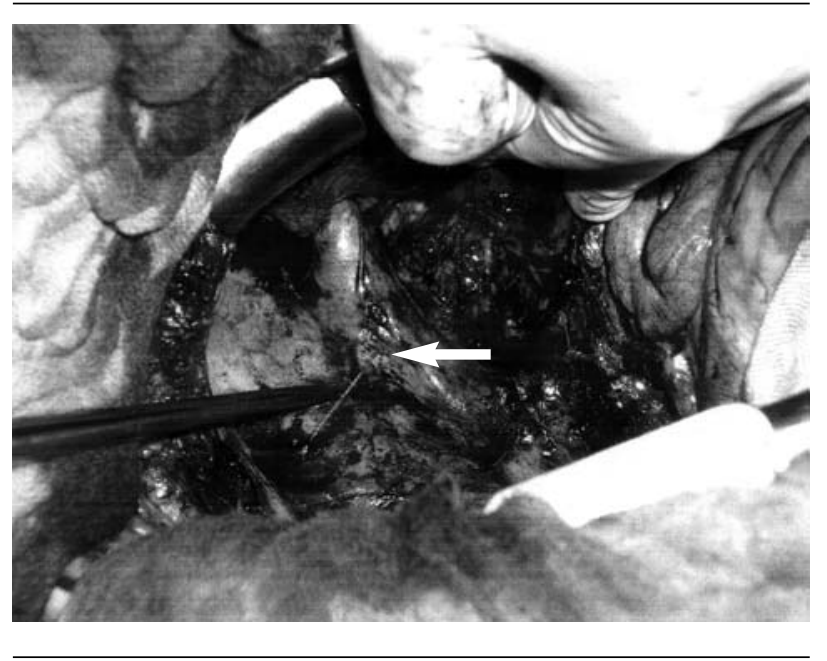

FIGURE View into the right pleural cavity. The catheter penetrates the pleura lateral to the spinal column. The tip of the catheter (arrow) is visible while the $5.5-\mathrm{cm}$ mark is not.

Accidental pleural puncture or the intrathoracic placement of catheters via a thoracic epidural are a rare, but potentially dangerous complication, especially in procedures with thoracotomy and one-lung-ventilation on the contralateral side. The median approach is thought to be less likely to produce pneumothorax and all reported cases to date occurred using a paramedian approach. This is the first report of pleural puncture by a thoracic epidural catheter using a median approach. ${ }^{3,4}$ Further investigation is necessary to demonstrate if pleural puncture in general is more likely to occur than previously thought and is more likely when using the paramedian approach.

One must assume that poor or ineffective analgesia, so-called "failed" epidurals may be due to misplacement and this includes interpleural position., ${ }^{2,5}$ The correct insertion of catheters into the epidural space can thereby only be verified by demonstrating a neural block and rare complications should be kept in mind when performing a thoracic epidural anesthesia. ${ }^{5}$

\author{
Britta Patermann MD \\ John Lynch FFARCS \\ Paul Schneider MD \\ Christoph Weigand MD \\ Sandra Kampe MD \\ University of Cologne, Cologne, Germany \\ E-mail: Sandra.Kampe@medizin.uni-koeln.de
}

\section{References}

1 Moraca RJ, Sheldon DG, Thirlby RC. The role of epidural anesthesia and analgesia in surgical practice. 
Ann Surg 2003; 238: 663-73.

2 Grieve PP, Whitta RK. Pleural puncture: an unusual complication of a thoracic epidural. Anaesth Intensive Care 2004; 32: 113-6.

3 Patt RB, Reddy S, Wu CL, Catania JA. Pneumothorax as a consequence of thoracic subarachnoid block. Anesth Analg 1994; 78: 160-2.

4 Miura K, Tomiyasu S, Cho S, Sakai T, Sumikawa K. Pneumothorax associated with epidural anesthesia. J Anesth 2004; 18: 138-40.

5 Koch J, Nielsen JU. Rare misplacements of epidural catheters. Anesthesiology 1986; 65: 556-7.

\section{Comparison of the accuracy of two dif-} ferent modes of continuous cardiac index measurement following rapid volume infusion

To the Editor:

Despite the current debate about the usefulness of the pulmonary artery catheter (PAC), ${ }^{1}$ cardiac index (CI) assessment by the thermodilution technique remains a frequently used technique. ${ }^{2}$ A PAC with a rapidresponse thermistor provides nearly continuous assessment of CI (CCI) and eliminates measurement variability associated with the intermittent bolus technique. We compared the accuracy of two different operation modes of CCI assessment (TREND mode, $\mathrm{CCI}_{\text {TREND }}$ and STAT mode, $\mathrm{CCI}_{\text {STAT }}$ ) with bolus thermodilution $\mathrm{CI}\left(\mathrm{CI}_{\mathrm{TD}}\right)$ measurement regarding their response to rapid volume infusion.

With approval of the local Ethics Committee and written informed consent, we studied 21 patients (17 males), aged 53 to $78 \mathrm{yr}$ (mean, $65.7 \mathrm{yr}$ ) undergoing elective coronary artery bypass grafting. Following induction of anesthesia, a right heart ejection fraction catheter (CCOmboV 774HF75; Edwards Lifesciences, Irvine, CA, USA) was inserted and connected to the Vigilance monitor system (Edwards Lifesciences, ) for $\mathrm{CCI}$ and intermittent $\mathrm{CI}_{\mathrm{TD}}$ measurement. The methodology of CCI measurement based on the pulsed warm thermodilution technique has been previously described in detail. ${ }^{3} \mathrm{CCI}_{\text {TREND }}$ reflects an average flow over the previous six to ten minutes and is updated every 30 to $60 \mathrm{sec}$. $\mathrm{CCI}_{\text {STAT }}$ does not contain a moving average filter but depends on some previous data for artefact suppression, and is also updated every 30 to 60 sec. Hemodynamic measurements were performed simultaneously after induction of anesthesia, when $\mathrm{CCI}_{\text {TREND }}$ had stabilized (Tl) and following volume
A

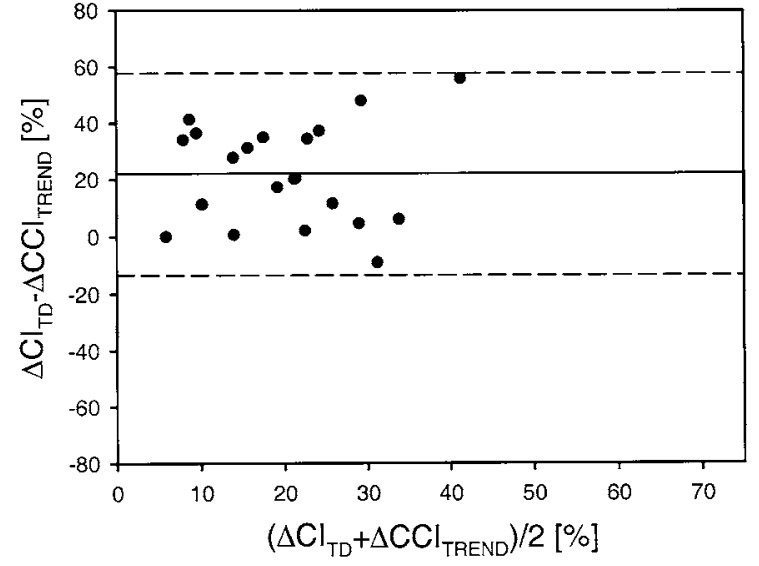

B

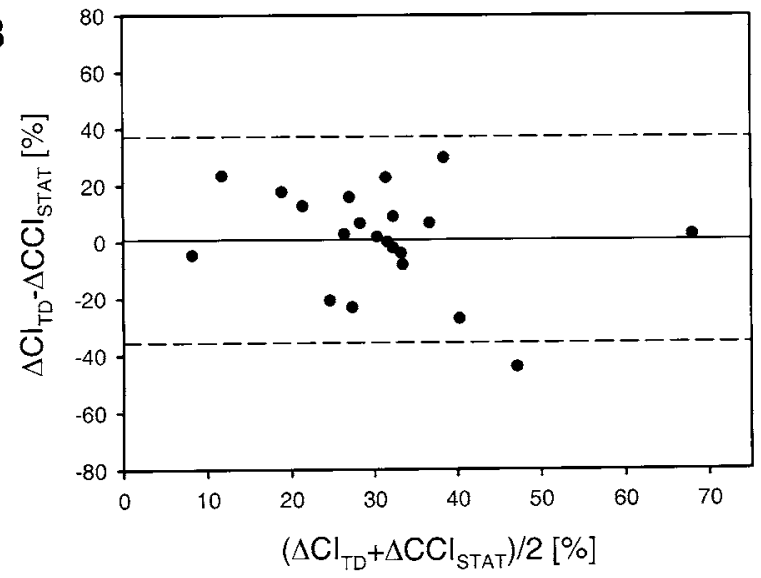

FIGURE Bland and Altman plot for comparison between cardiac index with bolus thermodilution $\left(\mathrm{CI}_{\mathrm{TD}}\right)$ and continuous assessment of cardiac index and TREND mode $\left(\mathrm{CCI}_{\text {TREND }}\right)(\mathrm{A})$ and between $\mathrm{CI}_{\mathrm{TD}}$ and continuous cardiac index and STAT mode $\left(\mathrm{CCI}_{\text {STAT }}\right)(\mathrm{B})$ for percent differences. The solid line represents the mean difference (bias) and the dashed lines represent the limits of agreement (mean difference $\pm 2 \mathrm{SD}$ of the difference).

replacement by infusion of 6\% HES 200/0.5 (7 $\mathrm{mL} \cdot \mathrm{kg}^{-1}$ ) with a rate of $1 \mathrm{~mL} \cdot \mathrm{kg}^{-1} \cdot \mathrm{min}^{-1}(\mathrm{~T} 2)$.

In all patients fluid challenge caused an increase in $\mathrm{CI}_{\mathrm{TD}}$ (range $5.9 \%$ to $69.2 \%$ ). The bias between $\Delta \mathrm{CI}_{\mathrm{TD}}{ }^{-}$ $\Delta \mathrm{CCI}_{\mathrm{TREND}}$ was $22.2 \%$ with a precision (SD of bias) of $17.8 \%$, and the bias between $\Delta \mathrm{CI}_{\mathrm{TD}}-\Delta \mathrm{CCI}_{\mathrm{STAT}}$ was $0.86 \%$ with a precision of $18.2 \%$, respectively. The relative error, defined as $100\left\{\left(\mathrm{CI}_{\mathrm{TD}^{-}}{ }^{-\mathrm{CCI}}\right) /\right.$ $\left.\left[\left(\mathrm{CI}_{\mathrm{TD}}+\mathrm{CCI}\right) / 2\right]\right\}$, was within $15 \%$ for just 27 out of 42 comparisons between the pooled data of $\mathrm{CI}_{\mathrm{TD}}$ and $\mathrm{CCI}_{\text {TREND }}$, compared with 40 measurements within $15 \%$ between the pooled data of $\mathrm{CI}_{\mathrm{TD}}$ and $\mathrm{CCI}_{\mathrm{STAT}}$. 